\title{
PADRÕES DE CIRCULAÇÃO EM SUPERFÍCIE E ALTITUDE ASSOCIADOS A EVENTOS DE CHUVA INTENSA NA REGIÃO METROPOLITANA DO RIO DE JANEIRO
}

\section{CARLOS ROBERTO WEIDE MOURA ${ }^{1}$, GUSTAVO CARLOS JUAN ESCOBAR ${ }^{2}$, KELEN MARTINS ANDRADE ${ }^{2}$}

\author{
${ }^{1}$ Centro Nacional de Monitoramento e Alerta de Desastres Naturais (CEMADEN), Cachoeira Paulista, SP, \\ Brasil \\ ${ }^{2}$ Instituto Nacional de Pesquisas Espaciais, Centro de Previsão de Tempo e Estudos Climáticos (INPE/CPTEC), \\ Cachoeira Paulista, SP, Brasil
}

carlos.moura@cemande.gov.br, gustavo.escobar@cptec.inpe.br, kelen.andrade@cptec.inpe.br

Recebido Agosto de 2012 - Aceito Janeiro de 2013

\begin{abstract}
RESUMO
Neste trabalho foi feita uma classificação sinótica de sequência de campos de pressão ao nível médio do mar (PNMM) e de altura geopotencial em $500 \mathrm{hPa}$, associado à ocorrência de precipitação intensa na cidade do Rio de Janeiro - RJ. Para obter os Padrões de Sequência Principal (PSP) da PNMM foi utilizada a metodologia de Análise de Componentes Principais (ACP) rotacionadas. Os resultados mostram três tipos de padrões sinóticos que causaram eventos extremos de chuva na cidade do Rio de Janeiro durante o período de 1997-2010, que representam aproximadamente 56\% da variância total dos casos. O padrão dominante mostra a passagem de frentes frias com trajetória predominantemente zonal. Já o segundo padrão está relacionado ao ingresso de frentes frias clássicas, acompanhadas de intensos anticiclones pós-frontais. Por último, observa-se um padrão relacionado ao posicionamento de um anticiclone à leste do Rio Grande do Sul, que gera ventos de quadrante sul no Rio de Janeiro. Palavras chave: classificação sinótica, eventos extremos, componentes principais

ABSTRACT: SURFACE AND ALTITUDE CIRCULATION PATTERNS ASSOCIATED TO INTENSE RAINFALL EVENTS OVER THE METROPOLITAN REGION OF RIO DE JANEIRO

In this study we performed a synoptic classification of a sea level pressure (SLP) sequence field and $500 \mathrm{hPa}$ geopotencial heights associated with occurrence of intense precipitation in the city of Rio de Janeiro - RJ. The rotated "Principal Component Analysis" (PCA) was used in order to find the basic patterns of SLP sequence and $500 \mathrm{hPa}$ geopotential heights. The outcomes show three dominant types of synoptic patterns that have caused intense rainfall events in the city of Rio de Janeiro along the period from 1997 to 2010 , which explain approximately $56 \%$ of the total variance of the cases. The main pattern shows cold front passages of with predominantly zonal trajectory. The second pattern is related to the entry of classical cold fronts, accompanied by intense postfrontal anticyclones. At last, it was observed a pattern related to the positioning of an anticyclone to the East of Rio Grande do Sul State, producing winds from the south quadrant over the city of Rio de Janeiro.
\end{abstract}

Keywords: synoptic classification, extreme events, principal components

\section{INTRODUÇÃO}

Os desastres naturais são causados pelo impacto de um fenômeno natural de grande intensidade sobre uma área ou região povoada, podendo ou não ser agravado pelas atividades antrópicas (Castro, 1999). A maioria dos desastres no Brasil está associada às instabilidades atmosféricas severas, que são responsáveis pelo desencadeamento de inundações, vendavais, tornados, granizos e escorregamentos (Marcelino, 2008). No Brasil, conforme EM-DAT (2007) (Emergency Disasters Data Base), ocorreram 150 registros de desastres no período no período $1900-2006$, sendo que $84 \%$ foram computadas a partir da década de 70 , demonstrando um aumento considerável de desastres nas últimas décadas. 
Nos últimos dois anos ocorreram dois dos maiores desastres naturais da história do país, que vitimaram centenas de pessoas, ambos no estado do Rio de Janeiro. No início de abril de 2010, ocorreram acumulados de precipitação superiores a $150 \mathrm{~mm}$ diários em várias localidades da Região Metropolitana do Rio de Janeiro (RMRJ), provocando deslizamentos que causaram 66 mortes na capital e 167 mortes em Niterói, deixando mais de 3 mil desabrigados e 11 mil desalojados. Em janeiro de 2011, a região serrana do Estado foi devastada por chuvas intensas. Em apenas 12 horas, foram registrados 222 $\mathrm{mm}$ de precipitação.

De acordo com o EM-DAT, este último foi o desastre natural mais severo da história do país, com cerca de 900 mortes (em Nova Friburgo, Teresópolis, Petrópolis, Sumidouro, São José do Vale do Rio Preto e Bom Jardim, sendo as duas primeiras, as cidades com maior número de vítimas), mais de 9.000 desabrigados e mais de 11.000 desalojados.

Alguns estudos indicam que o aumento dos desastres naturais pode estar diretamente vinculado às mudanças climáticas globais e aumento da frequência e intensidade de chuvas fortes. Merece destaque para o último relatório do Intergovernmental Panel on Climate Change (IPCC) de 2007, que aponta para um aumento das precipitações nas Regiões Sul e Sudeste e um agravamento da seca nas Regiões Norte e Nordeste do Brasil. Cabral et al. (2000) sugere ainda que o aumento da intensidade e da frequência de valores pluviométricos em megacidades, como Rio de Janeiro e São Paulo, podem estar associados a efeitos como ilha de calor (aumento de convecção), rugosidade (gerando turbulência) e quantidade de material particulado em suspensão (servindo como núcleos higroscópicos) derivados de poluição.

Sabendo desta relação direta entre ocorrência de desastres naturais versos eventos extremos de chuva, tornou-se evidente e indispensável à compreensão do padrão de circulação atmosférica associado a este tipo de fenômeno.

Dereczynski et al. (2009) fez uma análise dos eventos de chuvas intensas utilizando 10 anos de dados observados para a cidade do Rio de Janeiro. A análise dos eventos de chuvas intensas indicou que, dos 160 casos selecionados, $77 \%$ foram provocados por sistemas frontais.

Ide e Macedo (2004) relacionaram os sistemas meteorológicos atuantes com eventos de escorregamentos com vítimas fatais no estado de São Paulo (1996-2004). Os autores concluíram que o sistema responsável pela maior parte das ocorrências foi a ZCAS, seguido pelas frentes frias. Malvestio e Nery (2012) analisaram a variabilidade da precipitação pluvial do Sudeste do Brasil e relacionaram com a ocorrência de desastres naturais, e concluíram que o período de verão é o mais propício para a ocorrência de desastres naturais, especialmente durante a configuração da ZCAS.
A maioria dos trabalhos que analisa eventos de chuva forte se baseia na investigação de composição de casos (compostos), e permitem compreender climatologicamente a circulação associada a este tipo de episódios a partir de campos médios (Dereczynski et al. 2009, Lima et al. 2010). Porém, este tipo de metodologia não é suficiente para identificar as diferentes situações que conduzem à obtenção desse campo médio. Desta forma, para fins de prognóstico, as características médias não são suficientes para explicar a variabilidade da circulação (baixa, média e alta troposfera) associada à ocorrência de extremos de chuva.

Considerando-se que a ocorrência de eventos extremos de precipitação na Região Sudeste do Brasil está estreitamente relacionada com a variabilidade dos sistemas sinóticos, que afetam o continente sul americano, este trabalho tem por objetivo estudar o comportamento regional da circulação atmosférica associada chuva forte na cidade do Rio de Janeiro. A finalidade é fazer uma classificação sinótica desses eventos, possibilitando compreender a variabilidade da circulação atmosférica e desta forma contribuir para aprimorar a previsão de tempo.

\section{MATERIAL E MÉTODOS}

\subsection{Localização}

A cidade do Rio de Janeiro foi escolhida para realização deste estudo por deter, no âmbito estadual, a maior população, maior orçamento, maior participação das atividades econômicas, e extensa rede de infraestrutura e serviços. De maneira geral, as áreas urbanas do município têm se expandido de forma intensa em locais pouco adequados para as atividades humanas, determinando um aumento no número de desastres naturais, muitas vezes resultando em perdas de vidas humanas.

Assim, conhecer e avaliar as situações sinóticas causadoras de precipitação intensa para o município auxiliará no desenvolvimento de ferramentas de monitoramento e alerta de chuvas intensas, a fim de minimizar os impactos provocados pode este tipo de evento.

\subsection{Dados}

Neste estudo foram utilizados dados diários de precipitação, no período de 1997 até 2010, de nove estações meteorológicas do Rio de Janeiro - RJ, pertencentes à Fundação Geo-Rio, entre as quais: Copacabana, Jardim Botânico, Urca, Vidigal, Laranjeiras, Rocinha, Santa Tereza, Grajaú e Tijuca. As informações referentes à localização, endereço e ficha técnica das estações estão disponíveis em http://www2.rio.rj.gov.br/ georio/site/alerta/alerta.htm. 
Optou-se por realizar o estudo utilizando dados não só da estação chuvosa da Região Sudeste (novembro-abril), mas de todo ano, a fim de determinar a ocorrência de casos de chuva forte fora deste período.

Para a análise das sequências de campos de circulação em superfície e altitude, associados a eventos de chuva intensa no Rio de Janeiro, foram usados dados de Pressão ao Nível Médio do Mar (PNMM), e dados de altura geopotencial em $500 \mathrm{hPa}$, provenientes da Reanálise do NCEP/NCAR (National Center for Environmental Prediction/Nacional Center for Atmospheric Research) (Kalnay et al., 1996), disponíveis no endereço www. cdc.noaa.gov. A mesma base de dados foi utilizada para se obter as figuras de pressão a nível médio do mar, e direção e intensidade do vento e umidade específica no nível de 850 $\mathrm{hPa}$, para os casos altamente correlacionados com os Padrões de Sequência Principal.

\subsection{Critério para seleção dos casos de chuva intensa}

Existem diferentes critérios de seleção para casos de chuva intensa, que podem levar em conta aspectos relacionados à quantidade de chuva registrada em um determinado intervalo de tempo e a abrangência espacial desta chuva, ou somente um destes parâmetros. A climatologia também é utilizada por alguns autores para definir casos de chuvas intensas.

A Organização Meteorológica Mundial (OMM) define os seguintes limiares para a determinação de chuva forte ou muito forte: Chuva forte: de 25,1 a 50,0 milímetros por hora ou, no máximo 8,0 milímetros em 10 minutos; Chuva muito forte: acima de 50,0 milímetros por hora ou mais de $8,0 \mathrm{~mm}$ em 10 minutos (Oliveira et al., 1998). Espírito Santo e Satyamurty (2002), adotaram os limiares de $100 \mathrm{~mm}$ e $150 \mathrm{~mm}$ em 24 horas em seu estudo sobre eventos extremos de precipitação na Região Sudeste.

Teixeira e Satyamurty (2007) adotaram como critério de seleção de casos de chuvas intensas na Região Sul do Brasil, eventos nos quais a isoieta de $50 \mathrm{~mm}$ em 24 horas cobrisse uma área de no mínimo $10.000 \mathrm{~km}^{2}$. Harnack et al. (1999) identificaram os episódios com precipitação maior que $51 \mathrm{~mm}$, em um ponto de grade, em um período de 1 ou 2 dias. Em seguida, somente os casos que apresentaram cobertura espacial com quatro ou mais pontos de grade adjacentes, representando aproximadamente $10.000 \mathrm{~km}^{2}$, foram considerados como eventos intensos de chuva.

Carvalho et al. (2002) definiram como evento extremo de precipitação, aquele que proporcionou $20 \%$ ou mais do total climatológico sazonal em uma estação, em 24 horas. Chaves e Cavalcanti (2000) consideraram eventos extremos aqueles com precipitação diária acima de 300\% da média diária climatológica e com persistência de 3 dias. Liebmann et al. (2000) estudando a variabilidade interanual dos eventos de precipitação extrema diária no Estado de São Paulo, definem como evento extremo, aquele em que a precipitação diária excede uma porcentagem da sua média sazonal ou anual.

Neste estudo, a seleção dos casos de chuva intensa foi feita utilizando como limiar de chuva extrema diária o percentil de $95 \%$. Assim, quando o valor ultrapassava o limiar em pelo menos uma das nove estações, o caso era selecionado. Um total de 145 casos de chuva intensa foi selecionado. Os limiares variaram entre 42 e $65 \mathrm{~mm} /$ dia entre as nove estações meteorológicas escolhidas, e são apresentados na Tabela 1.

\subsubsection{Análise de Componentes Principais (ACP)}

A partir das datas dos dias associados a eventos extremos de chuva no Rio de Janeiro, obtidas segundo a aplicação do critério referido em 2.3, foram extraídas as situações sinóticas utilizando os campos de pressão ao nível do mar e os campos de altura geopotencial em 500 hpa provenientes do NCEP.

Para a determinação dos padrões associados a esses eventos foi realizada uma classificação sinótica das sequências de campos de pressão ao nível do mar e de altura geopotencial em $500 \mathrm{hPa}$. A sequência foi formada pelo campo de circulação dois dias antes do evento (dia-2), um dia antes (dia -1) e o dia do evento (dia 0). A metodologia utilizada foi a ACP com uma matriz de correlação em Modo - T (Green, 1978; Richman, 1986).

Existem dois tipos de ACP utilizados para analisar a variável observada tanto no espaço quanto no tempo. O primeiro chamado Modo-S está relacionado com a análise de séries temporais correspondentes a pontos no espaço. Isto significa que a variável estatística analisada corresponde a séries temporais de uma variável meteorológica, que pode ser considerada contínua no espaço e no tempo. Por outro lado, o Modo-T pode ser aplicado para classificar campos atmosféricos espaciais (Compagnucci e Salles, 1997; Escobar et al., 2004). Segundo Richman (1983) o Modo-T é uma ferramenta muito útil para sintetizar e reproduzir padrões de circulações, quantificando sua frequência e mostrando os períodos de tempo neles dominantes.

Os Padrões de Sequências Principais (PSP) foram obtidos usando a aproximação de Compagnucci et al. (2001). Nesta aplicação as variáveis são sequências de padrões espaciais de pressão ao nível do mar e de altura geopotencial em $500 \mathrm{hPa}$, que correspondem a um evento de chuva intensa, e, a matriz de correlação representa a correlação entre sequências para cada evento. Esta aproximação é considerada como uma extensão do tradicional ACP, com uma matriz de correlação em Modo-T, cujo objetivo principal é obter a evolução dos principais modos dominantes de circulação que permitam analisar a trajetória e comportamento dos sistemas sinóticos sobre determinadas áreas. 
Tabela 1 - Valores dos limiares de chuva intensa $(\mathrm{mm} /$ dia) para cada estação.

\begin{tabular}{c|c}
\hline ESTAÇÃO & LIMIAR $(\mathrm{mm} / \mathrm{dia})$ \\
\hline Copacabana & 42,8 \\
\hline Jardim Botânico & 57,0 \\
\hline Urca & 43,4 \\
\hline Vidigal & 49,2 \\
\hline Laranjeiras & 53,8 \\
\hline Rocinha & 65,4 \\
\hline Santa Tereza & 51,4 \\
\hline Grajaú & 44,2 \\
\hline Tijuca & 55,6 \\
\hline
\end{tabular}

Após a aplicação desta aproximação foi feita a rotação Varimax. A rotação das componentes principais tem como principal objetivo redistribuir a variância total dos dados utilizados, com o intuito de facilitar o significado físico das componentes obtidas (Richman, 1986). Para a determinação do número de componentes rotacionadas utilizou-se a regra do autovalor 1.0 (Richman et al., 1992).

Para a determinação das situações meteorológicas altamente correlacionadas com as componentes principais, foram utilizadas as séries temporais de "factor loadings", que representam as correlações entre cada variável (situação meteorológica real) e cada componente principal (Richman, 1986). A análise da série de "factor loadings" permite determinar a representatividade das componentes principais como situações sinóticas reais, valores próximos a 1 representam sequências de situações meteorológicas similares às sequências das componentes principais obtidas (Harman, 1976; Cattel, 1978).

\section{RESULTADOS}

\subsection{Classificação sinótica}

\subsubsection{Pressão ao nível do mar}

A aplicação da Análise de Componentes Principais identificou três PSP em superfície que explicaram aproximadamente $56 \%$ da variância total.

A Tabela 2 mostra as porcentagens da variância explicada e da variância acumulada pelas componentes.
A análise das componentes de peso (ou "factor loadings") permite avaliar a representatividade dos padrões como situações sinóticas reais. Valores próximos a 1 representam sequências de situações meteorológicas similares às sequências dos padrões obtidos (Harman, 1976; Cattel, 1978). As primeiras três componentes de peso mostraram valores maiores que 0,7 . Isto significa que os padrões de sequência teóricos e as situações sinóticas reais têm configurações similares. Os demais PSP não foram considerados neste trabalho já que explicam menos de $7 \%$ da variância. Esses padrões também representam situações meteorológicas especiais, porém menos frequentes.

Nas Figuras 1, 3 e 5 observam-se os três PSP (painéis superiores) e casos observados (painéis inferiores) altamente correlacionados com eles. Nas Figuras 2, 4 e 6 são mostrados os campos de umidade específica e de vento (direção e intensidade) no nível de $850 \mathrm{hPa}$, para os dias altamente correlacionados.

O primeiro padrão sinótico PSP1 (Figura 1- painéis superiores), mostra o deslocamento de um cavado frontal que no Dia-2 encontra-se entre o sul do Paraguai e Nordeste da Argentina, cujo ciclone extratropical associado é intenso e se localiza a sul de 50S. Este sistema frontal tem um deslocamento praticamente zonal, se deslocando pelo Sul e sul do Sudeste do Brasil no dia -1 , atingindo a região de estudo no dia 0 , quando provoca o evento extremo de precipitação. Neste dia nota-se também um alinhamento de uma área de baixa pressão desde o oeste da Região Norte até o Sudeste do Brasil, onde atua a frente fria.

O caso real altamente correlacionado (Figura 1- painéis inferiores) mostra no Dia -0 o cavado frontal na altura do Rio de Janeiro, e uma área de baixa pressão que se estende desde o sul da Região Amazônica até o Atlântico, acoplando-se ao cavado frontal. Esse alinhamento de áreas de baixa pressão desde a Amazônia até o oceano favoreceu a convergência de umidade de latitudes mais baixas em direção ao Estado Fluminense (Figura 2), sendo um dos fatores determinantes para ocorrência do evento de chuva intensa. Além disso, nota-se um aumento

Tabela 2 - Porcentagens da variância explicada e porcentagens da variância acumulada pelos três PSPs.

\begin{tabular}{c|c|c}
\hline PSP & POR. VAR. (\%) & POR. CUM. VAR. (\%) \\
\hline $1^{\circ}$ & 25,8 & 25,8 \\
\hline $2^{\circ}$ & 21,5 & 47,3 \\
\hline $3^{\circ}$ & 8,3 & 55,6 \\
\hline $4^{\circ}$ & 6,9 & 62,5 \\
\hline $5^{\circ}$ & 4,0 & 66,5 \\
\hline $6^{\circ}$ & 3,8 & 70,3 \\
\hline $7^{\circ}$ & 3,6 & 73,9 \\
\hline $8^{\circ}$ & 3,0 & 76,9 \\
\hline
\end{tabular}



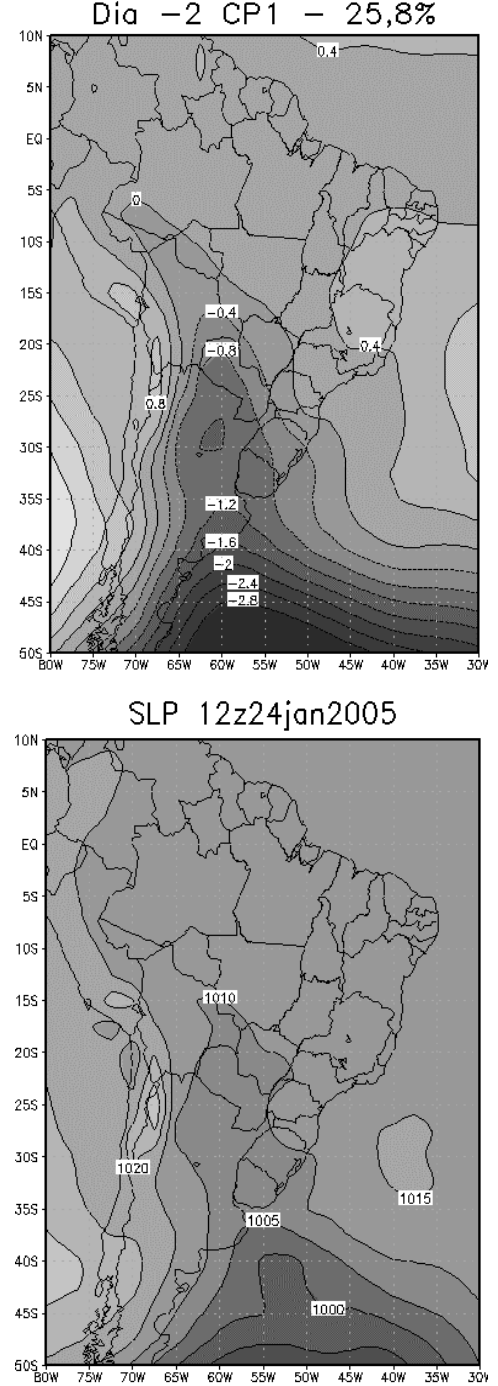

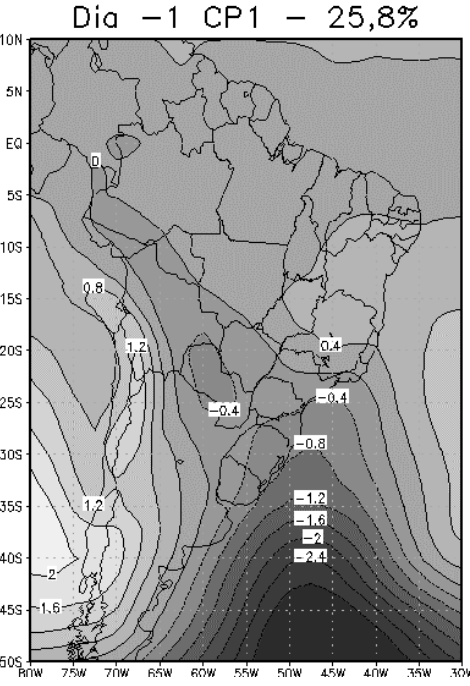

SLP 12z25jan2005

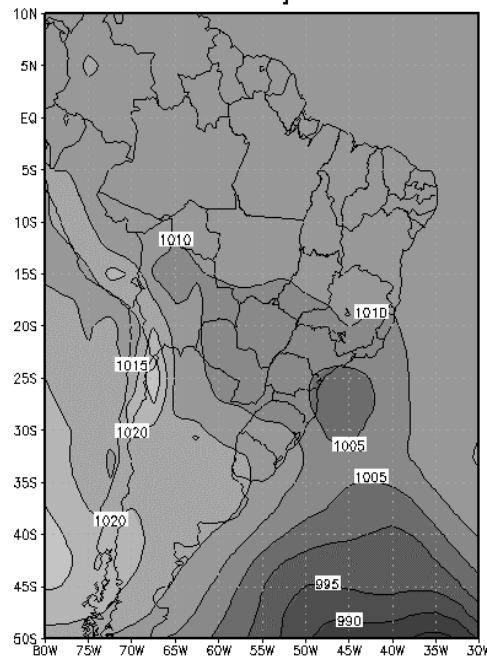

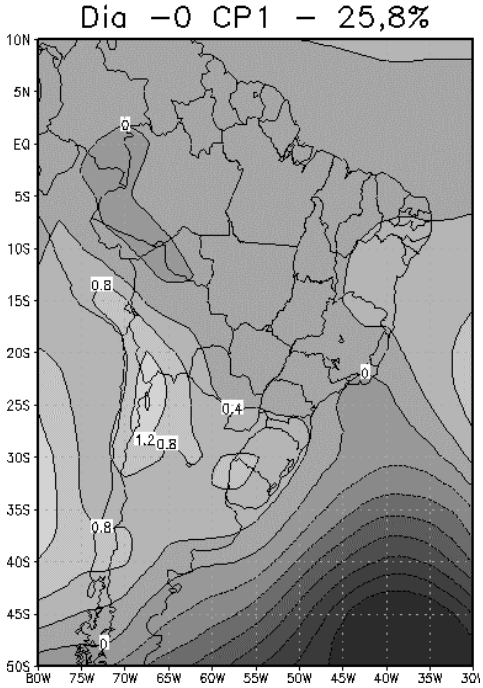

SLP 12z26jan2005

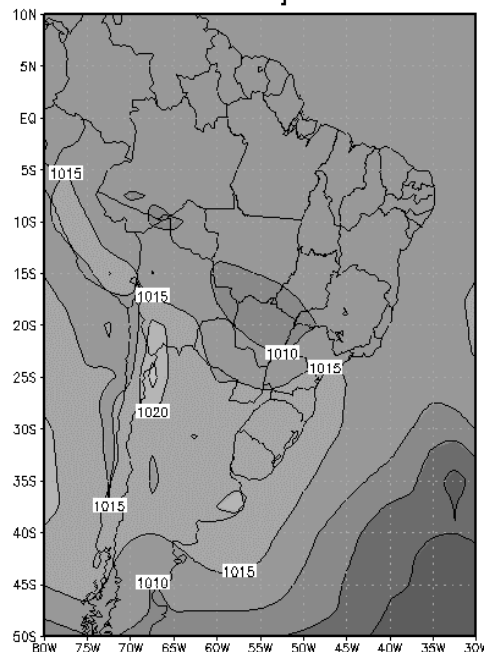

Figura 1 - Primeira Sequência de Componentes Principais (painéis superiores) e um caso observado (24/01/05 - 26/01/05) de pressão ao nível médio do mar altamente correlacionado (painéis inferiores).

significativo do conteúdo de umidade no nível de $850 \mathrm{hPa}$ sobre o Rio de Janeiro ao longo dos três dias em estudo, associado ao deslocamento do sistema frontal.

No verão, este padrão sinótico pode estar associado a episódios de Zona de Convergência do Atlântico Sul (ZCAS), como foi verificado em alguns dos casos altamente correlacionados. Um resultado similar foi encontrado por Escobar e Costa (2005), que fizeram uma classificação sinótica de episódios de ZCAS na América do Sul. Durante o inverno, este padrão sinótico está vinculado, principalmente a incursões de ar frio na América do Sul. Isto também foi verificado através de alguns dos casos altamente correlacionados com o PSP1.

O segundo padrão sinótico PSP2 (Figura 3 - painéis superiores), também está associado ao avanço de um típico sistema frontal frio desde o sul do continente até a Região Sudeste do Brasil. No dia -2 observa-se o sistema frontal sobre o Sul do Brasil, com o centro do anticiclone pós-frontal sobre o extremo sul do continente. No dia -1 a frente fria atinge o sul do estado de SP, chegando ao RJ no dia 0 . Neste dia o anticiclone pós-frontal fica intenso e abrangente, tomando conta de grande parte da Argentina, do Uruguai, Paraguai e o Sul do Brasil. Nota-se que o gradiente de pressão consegue penetrar até sul da região amazônica, atingindo parte dos Estados de Mato Grosso do Sul (MT), do Acre (AC) e de Rondônia (RO). Sistemas com esta intensidade são comuns no inverno, muitas vezes associados a episódios de friagens (Marengo et al., 1997). Este resultado permite concluir que, durante o inverno, também podem ocorrer eventos de chuva extrema na capital fluminense, porém com menor frequência em relação à estação chuvosa.

O caso real altamente correlacionado (Figura 3 - painéis inferiores) mostra a presença de um intenso anticiclone pósfrontal de $1035 \mathrm{hPa}$, avançando lentamente desde o sul do 

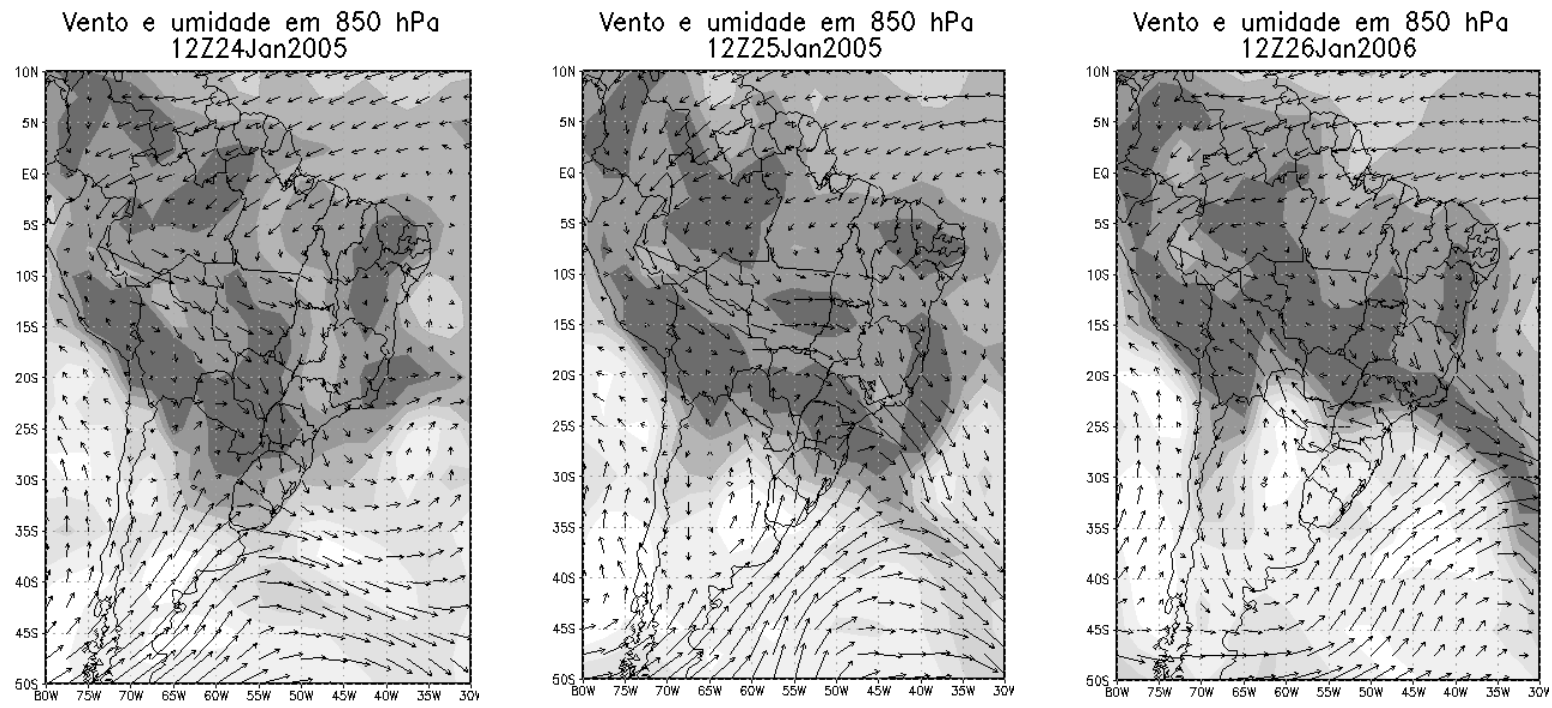

Figura 2 - Caso observado (24/01/05 - 26/01/05) de umidade específica e direção e intensidade dos ventos em 850 hPa altamente correlacionado.
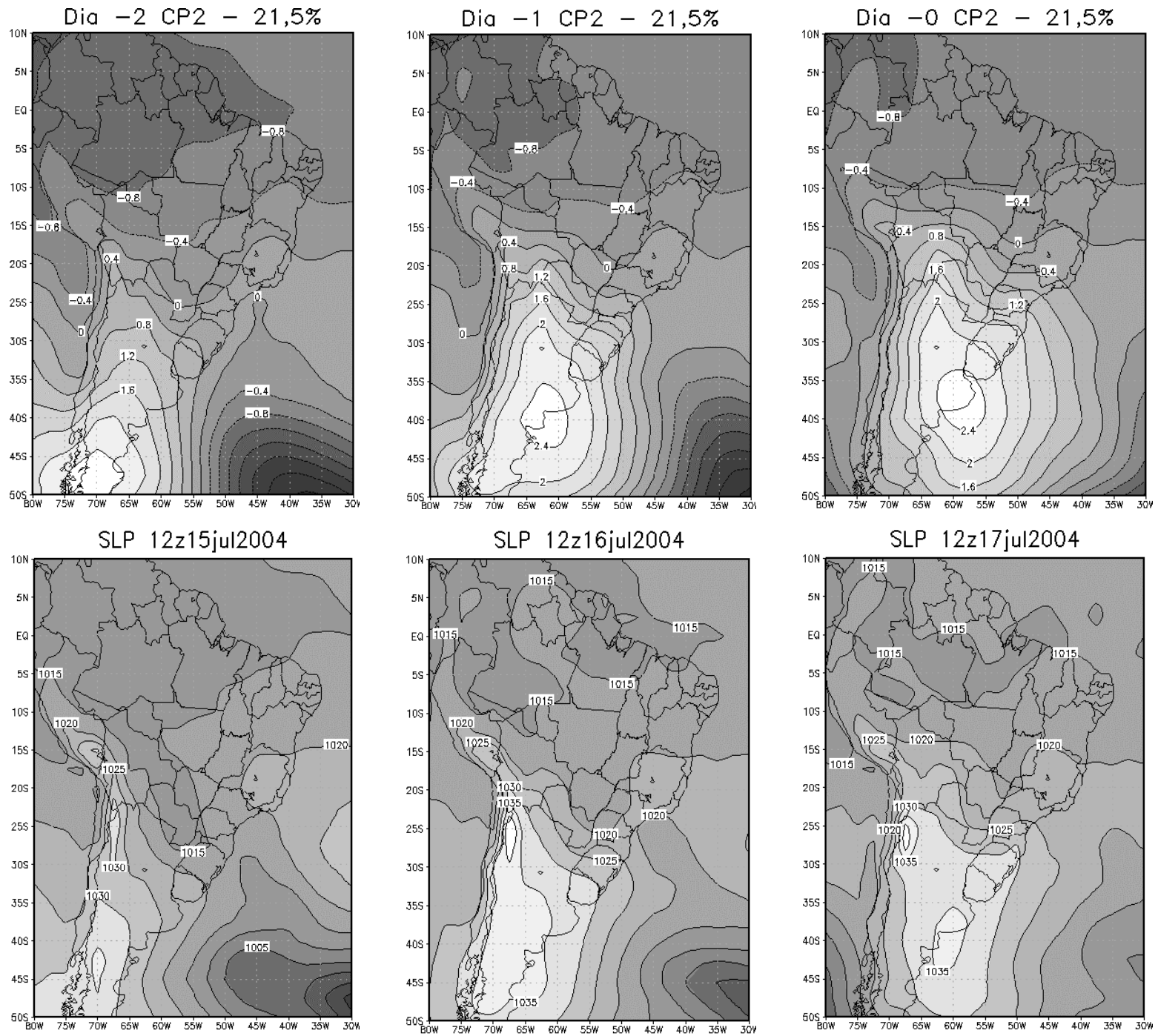

Figura 3 - Segunda Sequência de Componentes Principais (painéis superiores) e um caso observado (15/07/04 - 17/07/04) de pressão ao nível médio do mar altamente correlacionada (painéis inferiores). 
continente (dia -2) até o sul da Província de Buenos Aires (dia0 ). Nota-se que no dia -0 o anticiclone é amplo e abrangente, apresentando um gradiente de pressão entre o continente (ao longo da costa) e o oceano, gerando uma pista de vento sul e favorecendo a advecção de umidade do oceano em direção ao continente, como será discutido adiante.

Através da análise da Figura 4, nota-se que no dia -2 os ventos sobre o estado do Rio de Janeiro sopravam de quadrante nordeste, advectando ar mais seco do oceano e norte da Região Sudeste. Por outro lado, neste mesmo dia, a entrada do sistema frontal já organizava um canal de umidade desde a Região Amazônica, passando pelo Paraguai, até a Região Sul do Brasil e oceano Atlântico adjacente. No dia-1 observa-se o avanço do canal de umidade em direção ao sul da Região Sudeste, porém não tão bem configurado quanto o dia anterior. Por fim, no dia do evento de chuva intensa, nota-se uma quebra da convergência de umidade de latitudes mais altas, de modo que o aumento do teor de umidade sobre o Rio de Janeiro ocorre, principalmente, devido aos ventos de quadrante sul que atingem a cidade, advectando o ar mais úmido do oceano em direção ao continente.

O terceiro padrão PSP3 (Figura 5 - painéis superiores), mostra um ciclone extratropical (Dia -2) com centro afastado do continente $(45 \mathrm{~S} / 30 \mathrm{~W})$, e que estende o cavado frontal associado em direção ao Sudeste do país. Na retaguarda deste sistema, observa-se um anticiclone pós-frontal centrado sobre o Uruguai, que ao longo dos próximos dois dias (Dia -1 e Dia -0) se desloca lentamente para leste. No dia da ocorrência da chuva intensa (Dia -0) no Rio de Janeiro, o centro do anticiclone está ligeiramente a leste do RS, em 32S/45W.

Pode-se observar que a maneira como o anticiclone se desloca e posiciona, gera ventos de quadrante sul/sudeste sobre a cidade do Rio de Janeiro durante os três dias analisados. A continuidade dos ventos de quadrante sul advecta umidade perpendicularmente à costa, que combinado com o fator orográfico da cidade, podem ter provocado a chuva intensa no Dia -0. Este anticiclone pode também estar associado a um evento de bloqueio, dado ao seu lento deslocamento, porém, não pode-se afirmar devido ao curto período estudado (3 dias).

A Figura 5 (painéis inferiores) mostra um caso altamente correlacionado com o PSP3 (Figura 5 - painéis superiores). Nota-se que no dia -2, um cavado frontal chegou ao sul do RJ e se manteve praticamente estacionário durante os dias -1 e dia -0 . A estacionariedade desta frente é representada pela presença de um cavado invertido embebido no escoamento do anticiclone, direcionado no sentido noroeste/sudeste, posicionado justamente sobre o estado do Rio de Janeiro.

Nota-se ainda, na Figura 6, a persistência de um canal de umidade entre a Região Sudeste e o Atlântico ao longo dos três dias, devido à estacionariedade atmosférica. Este tipo de situação meteorológica, geralmente está associada com episódios de Zona de Convergência do Atlântico Sul (ZCAS), sendo este um dos principais sistemas causadores de chuvas intensas sobre o Sudeste do Brasil durante o verão. A ocorrência de transporte e convergência de umidade na baixa troposfera é um dos principais critérios para a identificação da ZCAS (Kodama, 1992; Sacramento Neto et al., 2010).

\subsubsection{Altura geopotencial em $500 \mathrm{hPa}$}

Uma análise da altura geopotencial em $500 \mathrm{hPa}$ também foi feita. Este nível, que representa a atmosfera média, tem a importante característica de guiar sistemas meteorológicos que
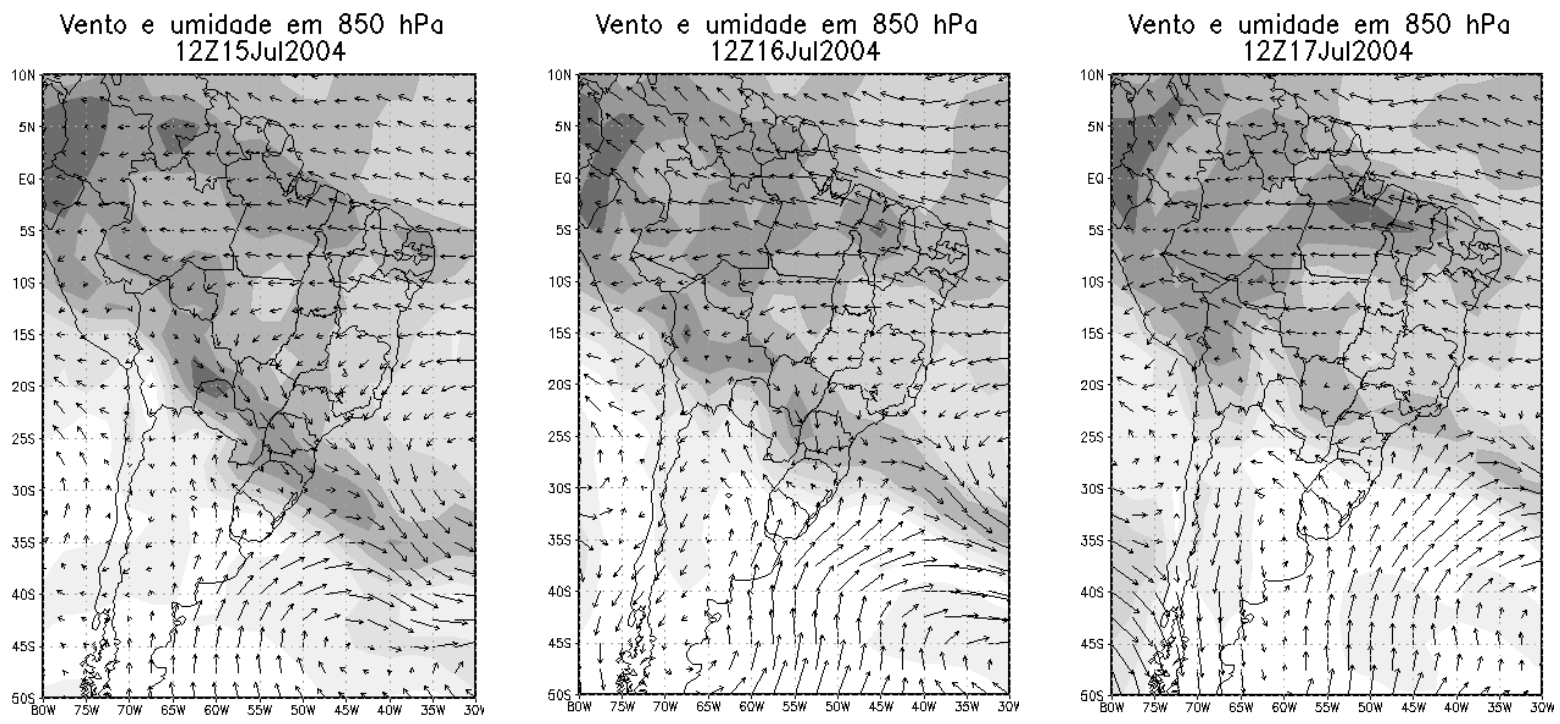

Figura 4 - Caso observado (15/07/04 - 17/07/04) de umidade específica e direção e intensidade dos ventos em 850 hPa altamente correlacionado. 


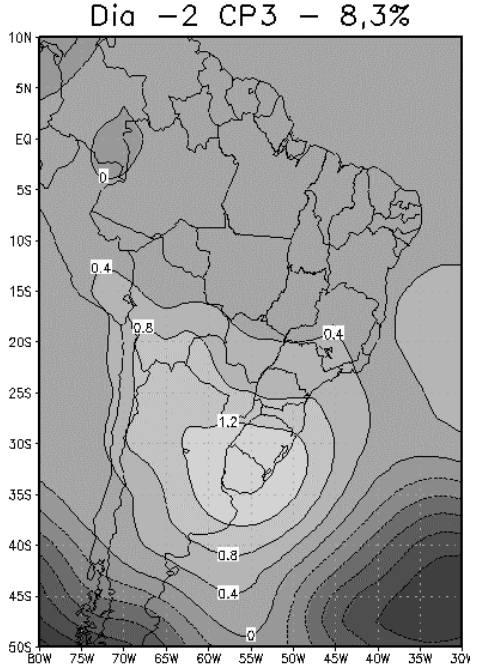

SLP 12z22oct2007

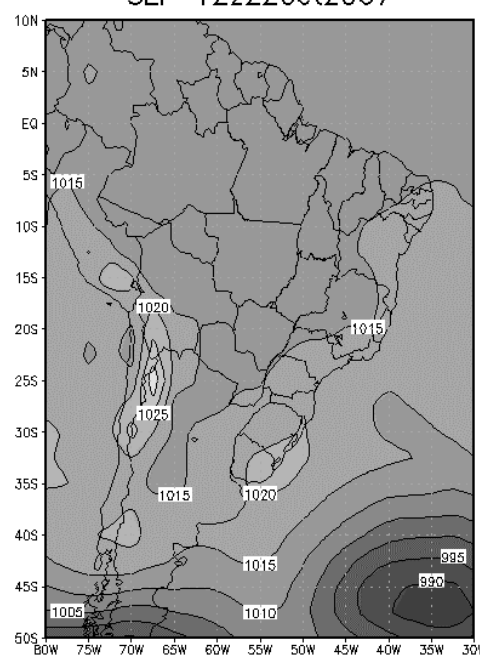

Dia $-1 \mathrm{CP} 3-8,3 \%$

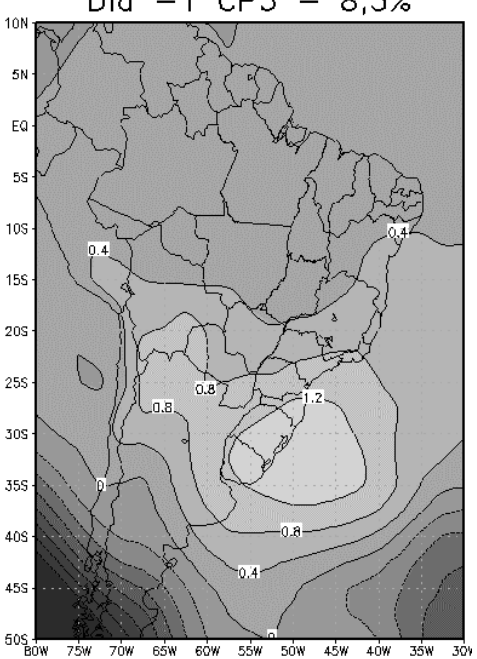

SLP 12z23oct2007

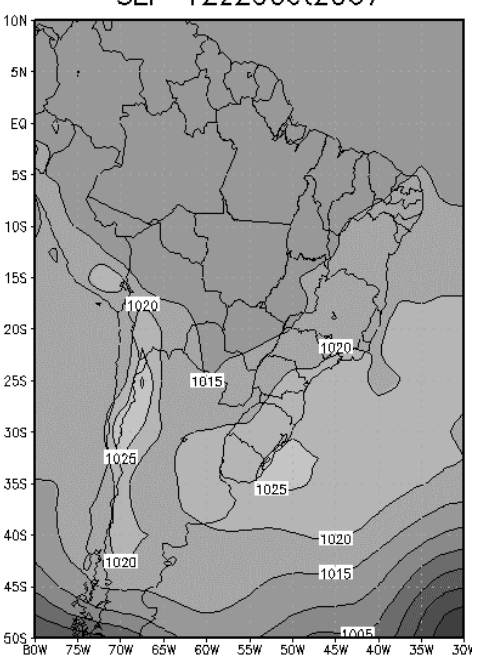

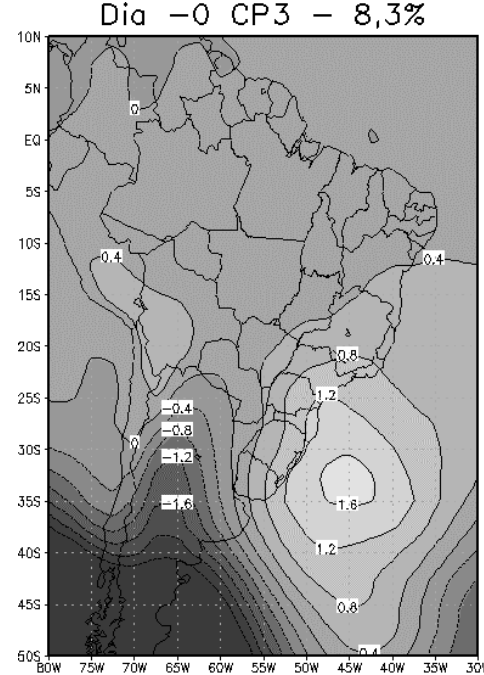

SLP $12 z 240 c t 2007$



Figura 5 - Terceira Sequência de Componentes Principais (painéis superiores) e um caso observado (22/10/07 - 24/10/07) de pressão ao nível médio do mar altamente correlacionada (painéis inferiores).
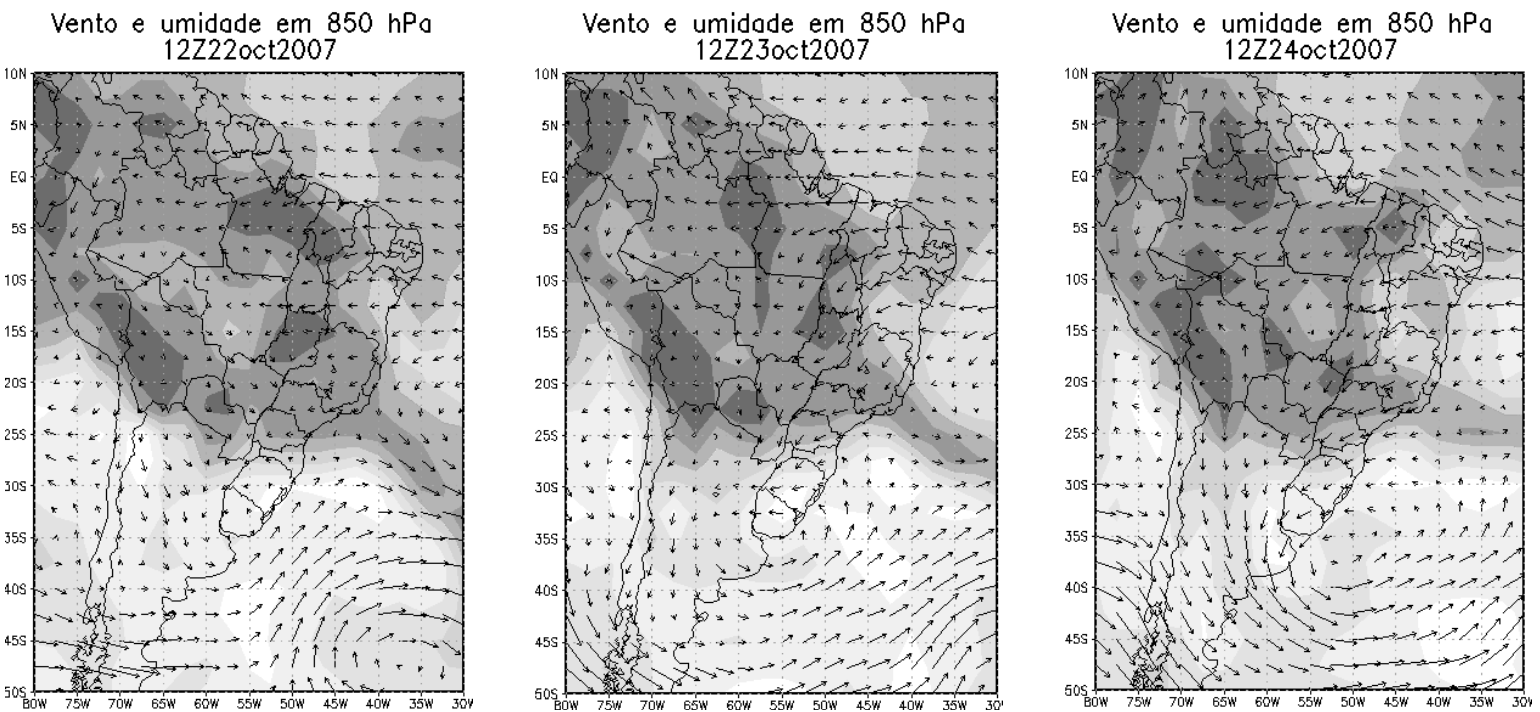

Figura 6 - Caso observado (22/10/07 - 24/10/07) de umidade específica e direção e intensidade dos ventos em 850 hPa altamente correlacionado. 
atuam em superfície, e consequentemente, grande importância na previsão do tempo.

A aplicação da ACP identificou três padrões de circulação em nível médio que explicaram $81 \%$ da variância total. A Tabela 3 mostra as porcentagens da variância explicada e porcentagens da variância acumulada pelas componentes.

Nas Figuras 7, 8 e 9 observam-se os três PSP (painéis superiores) e casos observados (painéis infeiores) altamente correlacionados com eles.

O primeiro padrão, PSP1, apresentado na Figura 7 (painéis superiores) mostra um significativo vórtice ciclônico centrado em 50S/35W (Dia -2), de onde desprende-se um cavado em direção ao continente, que atua entre a Província de Buenos Aires e o Uruguai. Este cavado que se apresenta bastante inclinado, tem em sua retaguarda um anticiclone com núcleo sobre o sul da Argentina. Ao longo dos próximos dois dias, os dois sistemas se deslocam ligeiramente para nordeste. No dia do evento (Dia -0) o cavado alcança o nordeste do RS, pelo oceano, de modo que o Rio de Janeiro fica sob a atuação da parte dianteira deste sistema. Esta configuração dá condição dinâmica para o levantamento de massa e ocorrência de chuva sobre o Estado fluminense, uma vez que os valores de ômega negativo se encontram na vanguarda do cavado.

O caso real altamente correlacionado (Figura 7 - painéis

Tabela 3 - Porcentagens da variância explicada e da variância acumulada pelos três PSPs.

\begin{tabular}{c|c|c}
\hline PSP & POR. VAR. (\%) & POR. CUM. VAR. (\%) \\
\hline $1^{\circ}$ & 30,2 & 30,2 \\
\hline $2^{\circ}$ & 28,5 & 58,7 \\
\hline $3^{\circ}$ & 22,0 & 80,7 \\
\hline
\end{tabular}

inferiores) mostra um cavado de onda longa, cujo eixo se estende de noroeste até o sudeste, com um máximo de vorticidade negativa localizado entre o centro da Argentina, Uruguai e o sul do RS, como pode ser inferido pelo campo de altura geopotencial mostrado. Ao sul deste cavado nota-se a presença de um intenso anticiclone que, no decorrer do período, se desloca lentamente adquirindo características de bloqueio. Esta configuração de altura geopotencial, em $500 \mathrm{hPa}$, favorece a incursão de massas de ar polares para latitudes mais baixas, uma vez que o fluxo predominante neste nível conduz os sistemas meteorológicos em superfície. Esta situação é comum durante o inverno do Hemisfério Sul, principalmente durante os meses de maio a setembro.

Um PSP similar foi encontrado por Escobar (2007), que fez uma classificação sinótica de sequência associada às ondas de frio na cidade de São Paulo - SP.

O segundo padrão de sequências principais, PSP2, mostrado na Figura 8 (painéis superiores) apresenta um anticiclone sobre o Atlântico, a leste de Buenos Aires, Uruguai e RS, que praticamente fica estacionária ao longo dos dias de estudo, possivelmente associada a uma alta pressão do tipo bloqueio. A sudoeste deste sistema observa-se um vórtice ciclônico com centro entre o Pacífico e o extremo sul do continente. $\mathrm{O}$ caso altamente correlacionado (Figura 8 - painéis inferiores) mostra um padrão de bloqueio menos intenso, com uma crista entre o Sudeste do país e o Atlântico, e na retaguarda um cavado.

Devido ao seu caráter persistente, os padrões de bloqueios podem manter a ocorrência de chuvas em uma mesma área durante vários dias.

A Figura 9 (painéis superiores) mostra o terceiro Padrão de Sequências Principais (PSP3). Este padrão de circulação em níveis médios da atmosfera apresenta um amplo cavado que
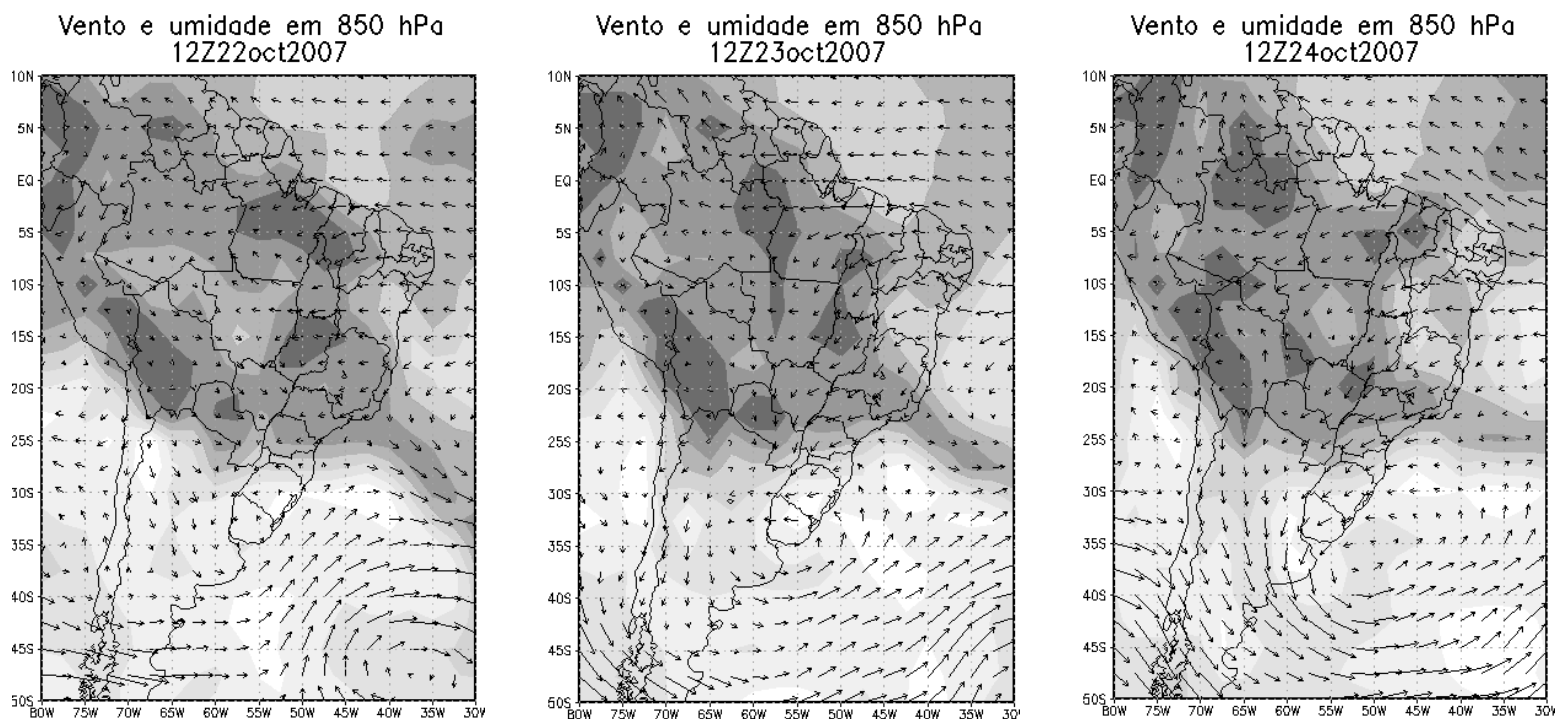

Figura 6 - Caso observado (22/10/07 - 24/10/07) de umidade específica e direção e intensidade dos ventos em 850 hPa altamente correlacionado. 

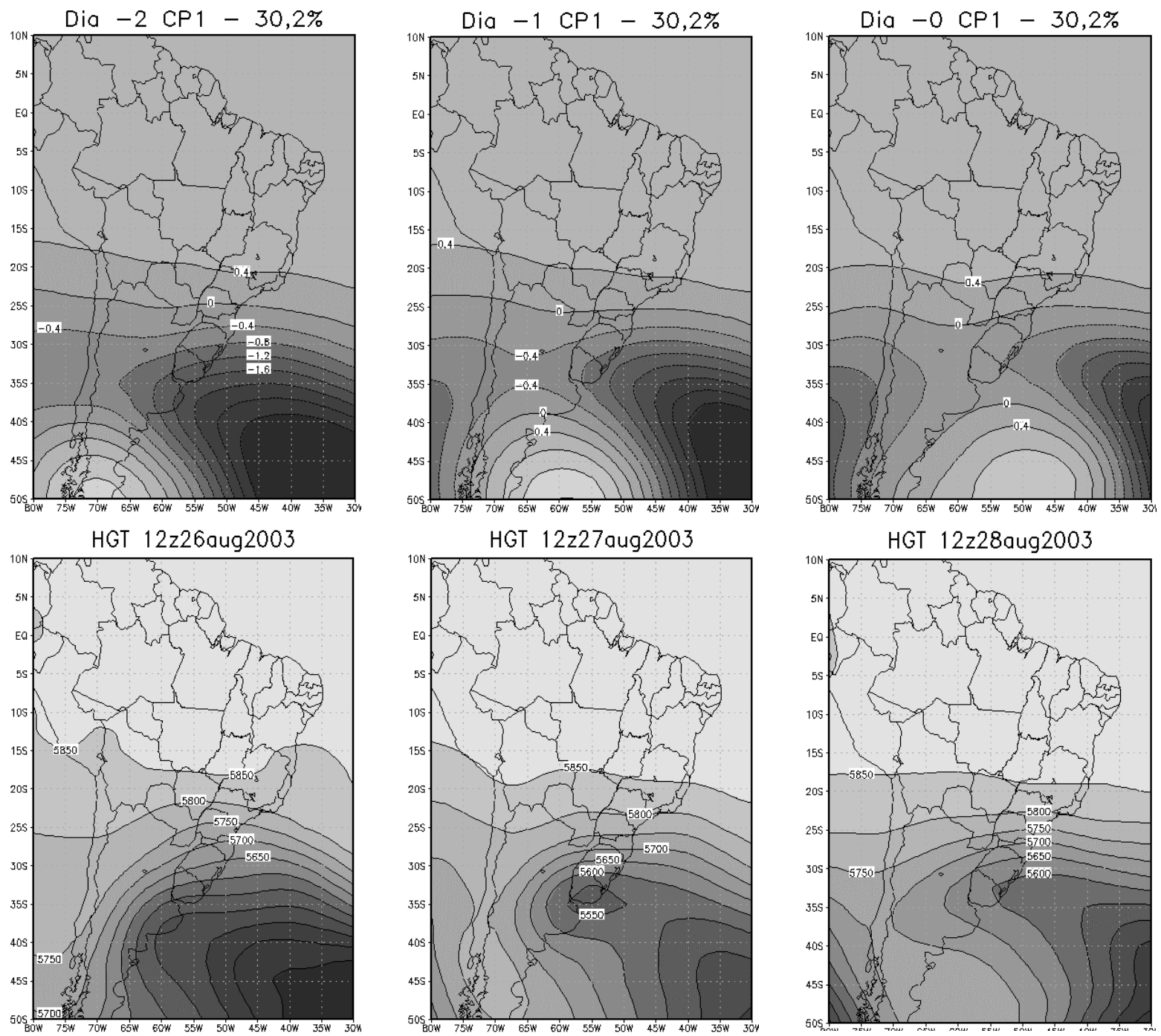

Figura 7 - Primeira Sequência de Componentes Principais (PSP 1)- painéis superiores e um caso observado de altura geopotencial em 500 hPa altamente correlacionado (26/08/03 - 28/08/2003) - painéis inferiores.

encontra-se restrito ao sul de $35 \mathrm{~S}$ no Dia -2, mas que ao longo dos próximos dois dias (Dia -1 e Dia -0) se amplifica e se desloca para leste, quase que zonalmente. Na retaguarda deste sistema nota-se um anticiclone, que cruza os Andes em forma de crista, posicionando seu núcleo sobre o Pacífico.

A sequência de situações sinóticas correspondentes aos dias 9, 10 e 11/02/2007 (Figura 9 - painéis inferiores) mostra um exemplo observado correlacionado com a componente principal analisada. Nota-se a amplificação do cavado durante os três dias de estudo, com a entrada de uma crista em sua retaguarda.

Este padrão de circulação em $500 \mathrm{hPa}$ está relacionado com o deslocamento de uma frente fria em superfície, que no dia -0 chega ao Sudeste do Brasil. Estes tipos de sistemas atuam no Brasil durante o ano todo, porém são mais frequentes durante o inverno.

\subsection{Relação entre superfície e altura geopotencial em $500 \mathrm{hPa}$}

Com o objetivo de analisar a estrutura vertical da circulação atmosférica associada a eventos de chuva intensa na região metropolitana do Rio de Janeiro, foram relacionados os campos altura geopotencial em $500 \mathrm{hPa}$ com aqueles de superfície. Essa relação foi feita através da comparação das séries de factor loadings correspondentes a cada PSP de superfície e altitude. A partir desta análise, foram determinadas duas correlações principais: o primeiro padrão de sequência principal de superfície (PSP1-Sup), com o terceiro padrão de sequência principal de $500 \mathrm{hPa}$ (PSP3500), e o segundo padrão de sequência principal (PSP2-Sup), com o primeiro padrão de sequência principal de $500 \mathrm{hPa}$ (PSP1-500). 

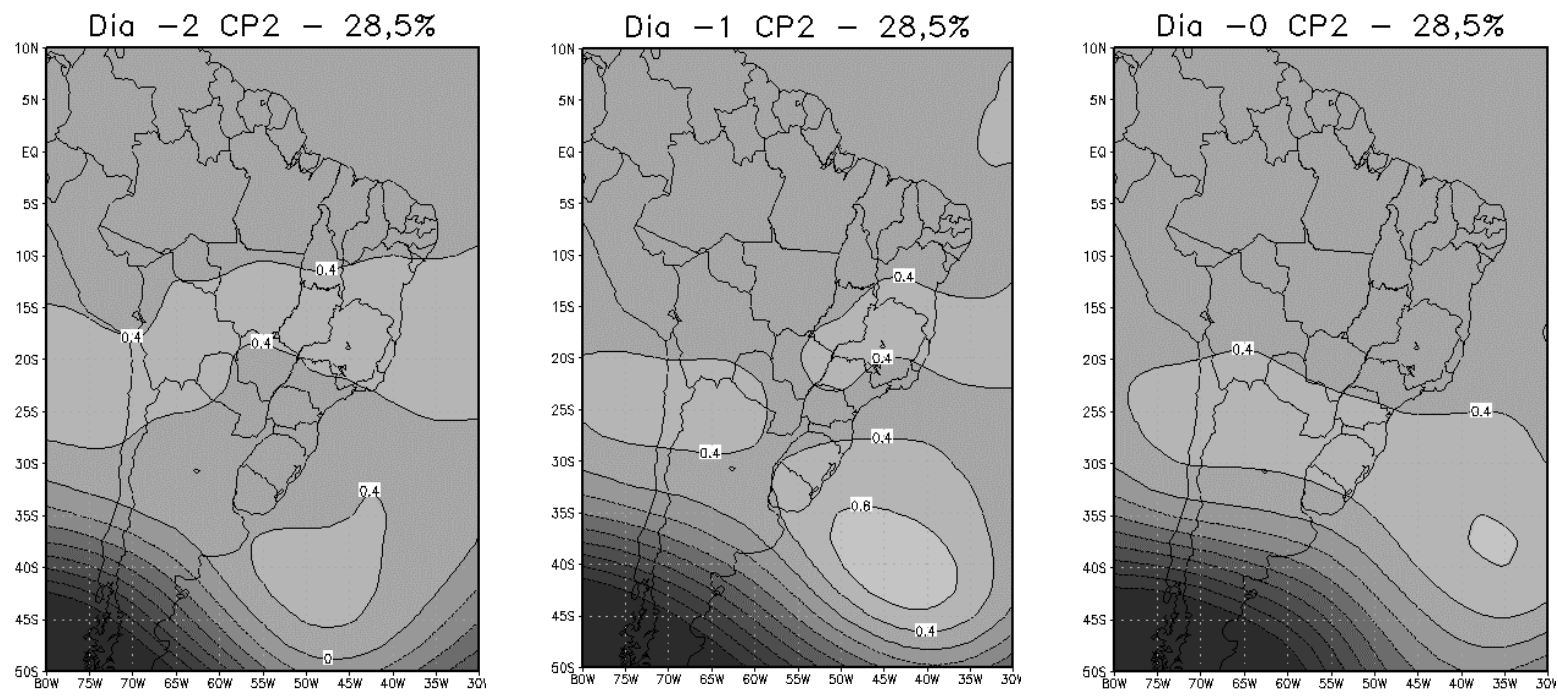

HGT 12z11mar2009
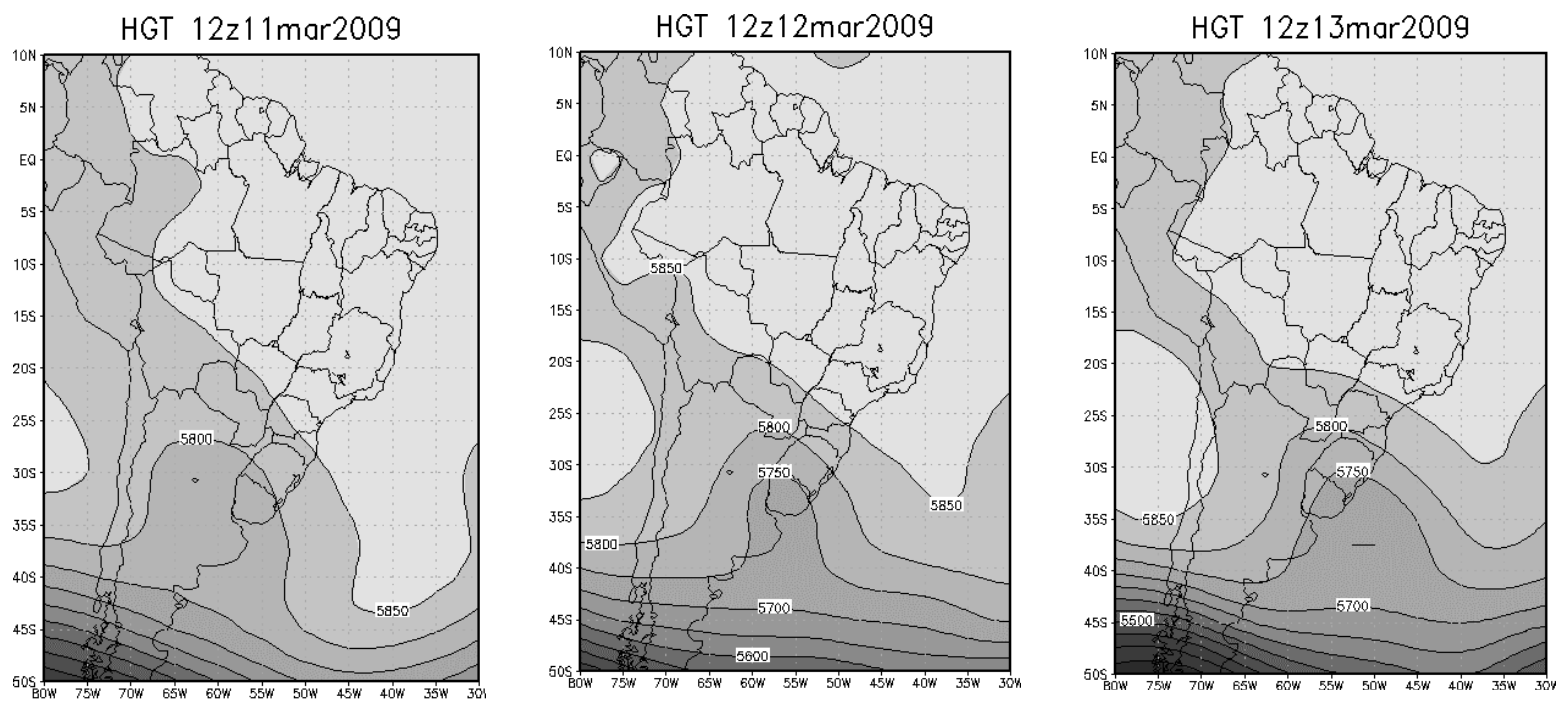

Figura 8 - Segunda Sequência de Componentes Principais (PSP 2) - painéis superiores e um caso observado de altura geopotencial em 500 hPa correlacionado (11/03/09 - 13/03/09) - painéis inferiores.

\section{i) PSP1-Sup em superfície com PSP3-500 em 500 hPa}

O PSP1-Sup (Figura 1 - painéis superiores) mostra um sistema frontal com ramo frio entre o Paraguai e a Província de Buenos Aires no dia -2, e ciclone extratropical intenso centrado em 50S/55W. Observa-se que este sistema se deslocou de maneira praticamente zonal, chegando ao Rio de Janeiro no dia -0 , provocando o episódio de chuva intensa. Simultaneamente, na retaguarda da frente fria observa-se a entrada de uma área de alta pressão, associada à alta pós-frontal, que cruza os Andes entre os paralelos 35 e $45 \mathrm{~S}$ nos dois primeiros dias do estudo (dia -2 e dia -1), estabelecendo-se entre o Sul do Brasil, Uruguai e norte da Argentina no dia -0 .

Analisando o PSP3-500 (Figura 9 - painéis inferiores), observa-se um padrão sinótico semelhante ao de superfície, que na verdade dá suporte e dita a maneira como a frente fria se desloca em superfície. Nota-se um vórtice ciclônico posicionado em $50 \mathrm{~S} / 55 \mathrm{~W}$ no dia -2 , que no decorrer dos próximos dois dias se desloca zonalmente, amplificando um cavado em direção ao continente, e dando suporte à frente fria em superfície. $\mathrm{Na}$ retaguarda deste cavado que se amplifica nota-se a entrada de uma crista, que cruza os Andes e se estende desde o centro da Argentina até o Sul do Brasil, diretamente associada à alta pressão pós-frontal em superfície.

\section{ii) PSP2 Sup em superfície com PSP1 500 em 500 hPa}

Na PSP2-Sup (Figura 2 - painéis superiores) observa-se a entrada de uma frente fria clássica sobre o país, com rápido deslocamento no sentido sudoeste/nordeste, e que consegue 

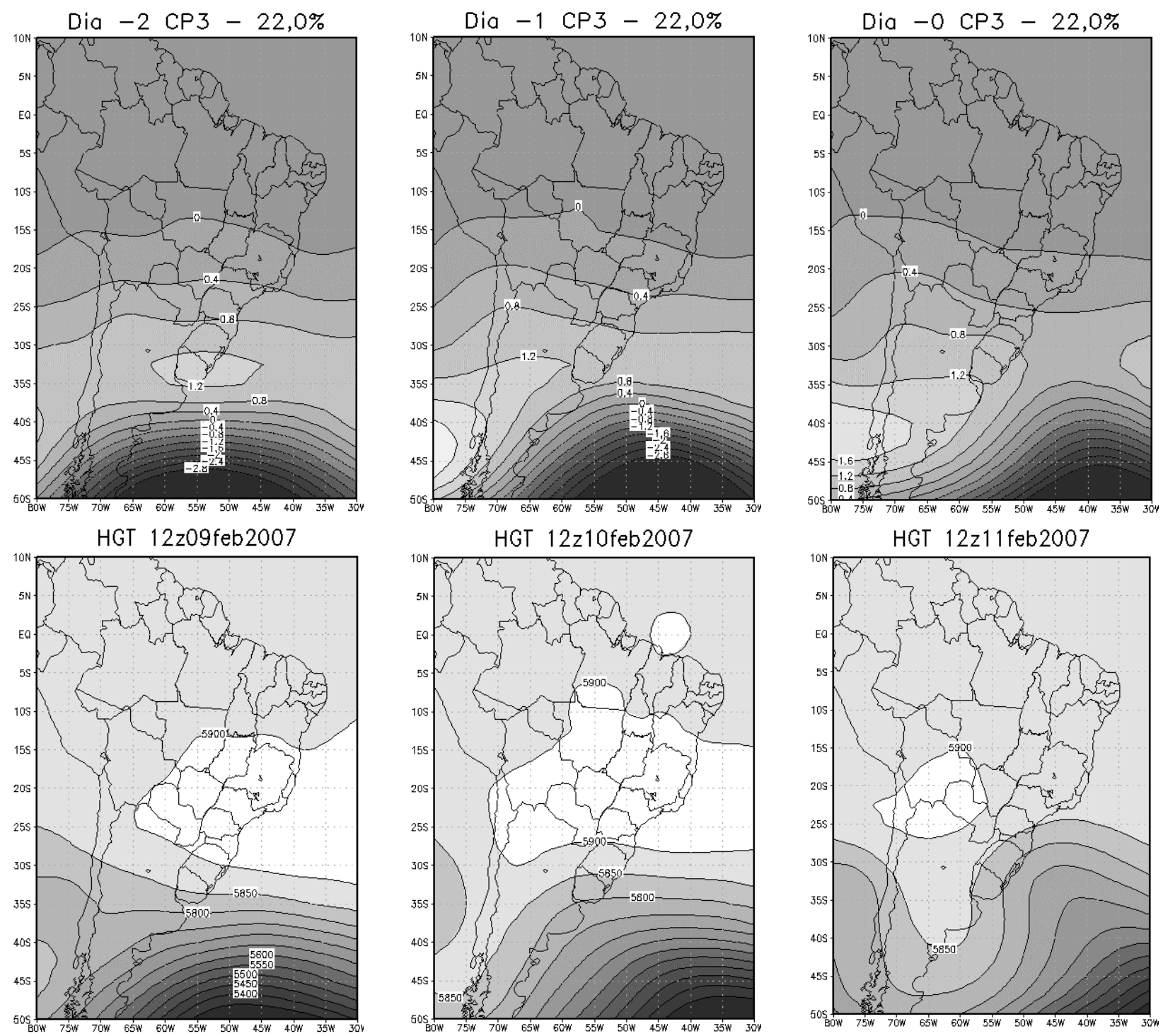

Figura 9 - Terceira Sequência de Componentes Principais (painéis superiores) e um caso observado (09/02/07 - 11/02/07) de altura geopotencial em $500 \mathrm{hPa}$ altamente correlacionado (painéis inferiores).

avançar até latitudes mais baixas. Este sistema frontal vem acompanhado de um significativo anticiclone pós-frontal que no dia -0 encontra-se centrado sobre a Província de Buenos Aires, mas com atuação bem ampla sobre o centro-sul do continente sul-americano.

Em $500 \mathrm{hPa}$ (Figura 7 - painéis inferiores) nota-se a presença de um significativo cavado baroclínico bastante inclinado, que também se desloca no sentido sudoeste/nordeste, determinando movimento do sistema frontal em superfície. A oeste deste cavado observa-se a área de alta pressão associada à alta pós-frontal em superfície. Este padrão sinótico é típico do inverno e está associado a fortes incursões de ar frio no continente sul-americano.

\section{CONCLUSÕES}

A análise da variabilidade dos campos de circulação em superfície e altura geopotencial em $500 \mathrm{hPa}$, associada com extremos de precipitação na cidade do Rio de Janeiro, mostra que existem diferentes padrões de circulação que podem produzir este tipo de evento.

Neste estudo foram apresentados o três primeiros Padrões de Sequências Principais (PSP) de pressão em superfície e de altura geopotencial em $500 \mathrm{hPa}$ obtidos, que explicam aproximadamente $56 \%$ e $81 \%$ da variância total dos casos, respectivamente. Por último, foram relacionados ambos os níveis (superfície e altitude) com o intuito de determinar 
os principais modos de variação de toda a estrutura vertical correspondente à baixa e média troposfera.

Os PSP de superfície mostraram: PSP1- a presença de uma clássica frente fria de verão, com fraca componente de deslocamento meridional; PSP2- a entrada de uma frente fria com intensa advecção de ar frio, típica de inverno; e PSP3- o lento deslocamento de um anticiclone ao longo de $35 \mathrm{~S}$, geralmente associado a um bloqueio atmosférico. Tanto o PSP1, quanto o PSP3 podem deflagrar eventos de Zona de Convergência do Atlântico Sul (ZCAS).

Através da análise dos campos de umidade específica e direção e intensidade dos ventos, observou-se que houve um aumento do conteúdo de umidade específica sobre o município do Rio de Janeiro no dia do evento de chuva intensa (dia -0), nos três casos altamente correlacionados estudados.

Os PSP de $500 \mathrm{hPa}$ mostraram: PSP1- um significativo cavado baroclínico com deslocamento bastante meridional, típico de inverno; PSP2- uma alta pressão com lento deslocamento geralmente associado a um bloqueio atmosférico; e PSP3- um amplo cavado de pouca amplitude que se desloca de maneira quase zonal.

Foram encontradas duas relações principais entre superfície e $500 \mathrm{hPa}$ a PSP1-Sup com PSP3-500, e a PSP2-Sup com PSP1-500.

Da primeira relação (PSP1-Sup/PSP3-500) pode-se concluir que o principal padrão deflagrador de chuva intensa na Região Metropolitana do Rio de Janeiro é a entrada de uma típica frente fria de verão, acompanhada de um cavado pouco amplificado em $500 \mathrm{hPa}$, que em certas ocasiões estão associadas ao desenvolvimento de uma Zona de Convergência Atlântico Sul (ZCAS). Da segunda relação (PSP2-Sup/PSP1-500) conclui-se que o segundo principal padrão deflagrador de chuva intensa no RJ é o avanço de uma intensa frente fria sobre o país, e significativo sistema de alta pressão pós-frontal, que avança até latitudes mais altas, inclusive estando associado a eventos de friagem. Em nível médio esta frente fria vem acompanhada do deslocamento de uma significativa onda baroclínica. Este último modelo conceitual é mais frequente durante o inverno, o que mostra que eventos de chuva intensa também podem ocorrer durante este período.

Os resultados alcançados neste trabalho permitem concluir que as frentes frias são os sistemas meteorológicos mais importantes em relação à ocorrência de chuva intensa. Elas podem provocar eventos extremos de chuva, tanto atingindo a região de estudo, ou ficando estacionária no oceano determinando um episódio de ZCAS. Porém, não se pode concluir que sempre que chega uma frente ao Estado RJ, ocorrerá chuva intensa. Por isso, faz-se necessário estudar o comportamento termodinâmico mais detalhado da atmosfera associado com este tipo de sistemas meteorológicos.

\section{AGRADECIMENTOS}

Os autores agradecem ao Conselho Nacional de Desenvolvimento Científico e Tecnológico (CNPq) pelo suporte financeiro através da Bolsa de Capacitação Institucional - PCI (Processo número 300454/2011-2) concedida ao primeiro autor.

\section{REFERÊNCIAS BIBLIOGRÁFICAS}

CABRAL, E.; FUNARI, F. T.; SALUM, S. T. ANÁLISE DA VARIAÇÃO DA PRECIPITAÇÃO DIÁRIA NO MUNICÍPIO DE SÃO PAULO SEGUNDO OS DIAS DA SEMANA._In: XI CONGRESSO BRASILEIRO DE METEOROLOGIA, 2000, Rio de Janeiro. Anais... Rio de Janeiro: 2000. p. 768-772.

CARVALHO, L.M.; JONES, C.; LEIBMANN, B. Extreme precipitation events in southeastern South America and large-scale convective patterns in the South Atlantic Convergence Zone. Journal of Climate, v.15, n. 17, p. $23772394,2002$.

CASTRO, A. L. C. Manual de planejamento em defesa civil. Vol.1. Brasília: Ministério da Integração Nacional/ Departamento de Defesa Civil, 1999. 133 p.

CATTELL, R. The scientific use of factor analysis: in Behavioral and Life Sciences. Plenum Press. New York and London, 1978.

CHAVES, R. R.; CAVALCANTI, I. F. A. Eventos extremos de precipitação sobre o sul do Nordeste. In: CONGRESSO BRASILEIRO DE METEOROLOGIA, 2000, Rio de Janeiro. Anais... Rio de Janeiro: SBMET, 2000. p. 10021008. 1CD-ROM.

COMPAGNUCCI, R.; SALLES, M.A. Surface Pressure Patterns during the year over Southern South America. Internatinal Journal of Climatology, v. 17, n. 6, p. 635-653, 1997.

COMPAGNUCCI, R.; D. ARANEO; CANZIANI, P. Principal sequence pattern analysis: A new approach to classifying the evolution of atmospheric systems. Internatinal Journal of Climatology, v. 21, p. 197-217, 2001.

DERECZYNSKI, C. P.; OLIVEIRA, J. S.; MACHADO, C. O. Climatologia da precipitação no município do Rio de Janeiro. Revista Brasileira de Meteorologia, v. 24, n.1, p. 3171-3185, 2009.

EM-DAT EMERGENCY DATABASE. OFDA/CRED - The Office of US Foreign Disaster Assistance/Centre for Research on the Epidemiology of Disasters - Université Catholique de Louvain, Brussels, Belgium, 2007. Disponível em: http://www.emdat.be/ Database. Acesso em: 02 jul. 2012.

ESCOBAR, G.C.J. Padrões Sinóticos Associados a ondas de frio na cidade de São Paulo. Revista Brasileira de Meteorologia, v.22, n.2, p.240-253, 2007. 
ESCOBAR, G. C. J.; COMPAGNUCCI, R. H.; BISCHOFF, S. A. Sequence Patterns of $1000 \mathrm{hPa}$ and $500 \mathrm{hPa}$ geopotential height fields associated with cold surges in Buenos Aires. Atmosfera, v 12, n. 2, p. 69-89, 2004.

ESCOBAR, G. C. J.; COSTA, I. C. Situações meteorológicas associadas a episódios da Zona de Convergência do Atlântico Sul (ZCAS). IX CONGRESSO ARGENTINO DE MEteOrologíA, 2005, Buenos Aires. Anais... Buenos Aires: 2005

ESPÍRITO SANTO, C.; SATYAMURTY, P. Eventos extremos de precipitação na Região Sudeste do Brasil e redondezas no período de 1997-2001. In: CONGRESSO BRASILEIRO DE METEOROLOGIA, 12., 2002, Foz do Iguaçu. Anais... Rio de Janeiro: SBMET, 2002. p. 397 402. 1CD-ROM.

GREEN, P. Analysing Multivariate Data. The Dryden Press. Illinois, U.S.A, 519, 1978.

HARMAN, H. Modern Factor Analysis. The University of Chicago Press Chicago, IL, 1976.

HARNACK, R. P.; APFFEL, K.; CERMACK, J. R. Heavy precipitation events in New Jersey: attendant upper air conditions. Weather and Forecasting, v. 14, n. 6, p. 933954, 1999.

IDE, F. S.; MACEDO, E. S. Sistemas meteorológicos associados a escorregamentos com vítimas fatais no Estado de São Paulo de 1996 a 2004. In: SIMPÓSIO BRASILEIRO DE DESASTRES NATURAIS, 1., 2004, Florianópolis. Anais... Florianópolis: GEDN/UFSC, 2004. P. 591-691.

IPCC - Intergovernmental Panel on Climate Change. Climate Change 2007: The Physical Science Basis. Summary for Policymakers.

KALNAY E. et al. The NCEP/NCAR 40-year reanalysis Project. Bulletin of American Meteorology Society, v.77, n.3, p. 437-471, 1996.

KODAMA, Y. M. Large-scale common features of subtropical precipitation zones (the Baiu frontal zone, the SPCZ, and the SACZ). Part I: Characteristics of subtropical frontal zones. Journal of Meteorological Society of Japan, v. 70, p. 813-835, 1992.

LIEBMANN, B.; JONES, C.; CARVALHO, L. M. V. DE. Interannual variability of daily extreme precipitation events in the State of São Paulo, Brazil. Journal of Climate, v. 14, p. 208-218, 2000.

LIMA, K. C.; FERNANDES J. P. R.; SATYAMURTY, P. Chuvas intensas no Sudeste do Brasil: influência das anomalias de temperatura da superfície do mar e da topografia. In: XVI CONGRESSO BRASILEIRO DE METEOROLOGIA, 2010, Belém do Pará. Anais... Belém do Pará, 2010. p. 309-319.
MALVESTIO, L. M.; NERY, J. T. Variabilidade da precipitação pluvial do sudeste do Brasil e desastres naturais nos verões de 96 e 97. In: I CONGRESSO BRASILEIRO DE DESASTRES NATURAIS, 2012, Rio Claro-SP. Anais... Rio Claro, 2012.

MARCELINO, E. V. Desastres naturais e geotecnologias: conceitos básicos. Cadernos Didáticos n.1. Instituto Nacional de Pesquisas Espaciais - INPE, Santa Maria, 38p, 2008.

MARENGO, J.A.; NOBRE, C.A.; CULF, A.D. Climatic Impacts of "Friagens" in forested and deforested areas of the Amazon Basin. Journal of Applied Meteorology, v. 36, p 1553-1566, 1997.

OLIVEIRA, N., FOGACCIA, C.V.C., ALMEIDA R.M.B., Caracterização preliminar das chuvas intensas no Estado de São Paulo, In: X CONGRESSO BRASILEIRO DE METEOROLOGIA, 1998, Brasília. Anais... Brasília, 1998

RICHMAN, M. Specification of complex modes of circulation with T-mode factor analysis. In: II INTERNATIONAL CONFERENCE ON STATISTICS AND CLIMATE, 1983, Lisbon. Anais... National Institute of Meteorology and Geophysics, 1983. p. 511-518.

RICHMAN, M. Rotation of Principal Components. Journal of Climatology, v. 6, n. 3, p. 293-335, 1986.

RICHMAN, M.; ANGEL, J.; GONG, X. Determination of Dimensionality in Eingenanalysis. In: V INTERNATIONAL MEETING ON STATSTICAL CLIMATOLOGY, 6., 1992, Canadá. Anais... Canadá, 1992. p. 229-235.

SACRAMENTO NETO, O. B.;ESCOBAR, G. C. J. ; SILVA, P. E. D. Método objetivo para identificar episódios de Zonas de Convergência de Umidade (ZCOU) no ambiente operacional do Centro de Previsão de Tempo e Estados Climáticos - CPTEC. In: XVI CONGRESSO BRASILEIRO DE MeteorologiA, 2010, Belém do Pará. Anais... Belém do Pará, 2010

TEIXEIRA, M. S.; SATYAMURTY, P. Dynamical and synoptic characteristics of heavy rainfall episodes in southern Brazil. Monthly Weather Review, v. 135, p. 598-617, 2007. 